\title{
PENGARUH KUALITAS PELAYANAN TERHADAP KEPUASAN NASABAH PADA PERUM PEGADAIAN CABANG MASAMBA
}

\author{
KUSNANDI, IKBAL, SAHARUDDIN
}

\begin{abstract}
ABSTRAK
Kualitas pelayanan merupakan salah satu atribut yang penting dalam perusahaan jasa keuangan.

Tujuan dilakukannya penelitian adalah sebagai berikut :

Untuk membuktikan apakah kualitas pelayanan yang diukur dengan bukti Fisik(Tangible), Jaminan (Assurance), Kepedulian (Emphaty), berpengaruh terhadap kepuasaan nasabah pada PERUM Pegadaian Cabang Masamba. Dan untuk menganalisis faktor yang berpengaruh dominan terhadap kepuasan nasabah pada PERUM Pegadaian Cabang Masamba.

Berdasarkan hasil penelitian ditemukan persamaan regresi sebagai berikut :

$Y=(-4,061)+0,103 X_{1}+0,337 X_{2}-0,795 X_{3}$.

$b_{0}=(-4,061)$, Mempunyai arti $X_{1} ; X_{2} ; X_{3}=0$ maka kepuasan nasabah PERUM Pegadaian Cabang Masamba mengalami penurunan sebesar (-4,061).

$b_{0}=(-4,061)$, Mempunyai arti $X_{1} ; X_{2} ; X_{3}=0$ maka kepuasan nasabah PERUM Pegadaian Cabang Masamba mengalami penurunan sebesar $(-4,061)$.

$b_{1}=0,103 X_{1}$, Artinya variabel bukti $\left(X_{1}\right)$ mempunyai oengaruh positif terhadap kepuasan nasabah PERUM pegadain Masamba.

$b_{2}=0,337 X_{2}$, Variabel kepedulian $\left(X_{2}\right)$ mempunyai pengaruh positif terhadap kepuasan nasabah.

kesimpulan dari hasil penelitian ini terdapat dua variabel yang dapat membuktikan hipotesis yang menduga bahwa dimensi kualitas layanan bukti fisik, jaminan, dan kepedulian berpengaruh signifikan terhadap nasabah pada PERUM pegadaian Masamba yaitu variabel jaminan (X2) dan kepedulian (X3) sedangkan satu variabel lainnya yaitu bukti fisik (X1) tidak diterima atau tidak terbukti kebenarannya.
\end{abstract}

Kata Kunci: Kualitas Pelayanan, Kepuasan nasabah, PERUM pegadaian. 


\section{Pendahuluan}

\section{Latar Belakang}

Pegadaian pertama kali lahir di Sukabumi tahun 1901 pada zaman penjajahan Belanda, selanjutnya sejak awal kemedekaan Pegadaian dikelola oleh Pemerintah dan sudah beberapa kali berubah status, yaitu sebagai Perusahaan Negara sejak 01 Januari 1961 kemudian berdasarkan PP No.7/1969 menjadi Perusahaan Jawatan (PERJAM) dan berdasarkan PP No.10/1990 yang diperbarui dengan PP No. 103/2000 berubah menjadi Perusahaan Umum (PERUM) hingga sekarang.

Sebagai sebuah perusahaan yang bergerak dibidang jasa keuangan, PERUM Pegadaian yang selama ini menikmati monopoli dibidang jasa gadai mulai menghadapi berbagai ancaman akibat persaingan yang semakin ketat disektor jasa keuangan. Lahirnya Undang- Undang Anti Monopoli membuat tumbuhnya berbagai lembaga keuangan yang menawarkan jasa gadai menggunakan istilah Syariah, misalnya BRI Syariah, Mandiri Syariah, Danamon Syariah serta keberadaan took emas yang membuka praktek gadai dan menjamunya produk kredit tanpa agunan sebagai alternatif solusi atas kebutuhan dana masyarakat.

Bagi perusahaan jasa, pelayanan yang dapat memuaskan pelanggan menjadi bagian yang sangat penting agar jasa keuangan yang diberikan tetap memimpin pasar. Loyalitas pelanggan akan terbentuk akibat pelayanan standar prima yang diterapkan oleh semua karyawan sehingga persepsi loyalitas bukan pada karyawan tetapi pada perusahaan. Setiap karyawan perusahaan umum pegadaian sekaligus berfungsi sebagai marketer perusahaan yang harus mampu melakukan personal branding. Karyawan harus mampu membuat perusahaan mendapat kepercayaan nasabah dan menjaga loyalitas nasabah untuk menjamin masa depan perusahaan.

Kualitas pelayanan merupakan salah satu atribut yang penting dalam perusahaan jasa keuangan. Menurut Parasuraman, 1988 (dalam Lupiyoadi 2008 : 182) ada lima dimensi yang relevan untuk menjelaskan kualitas pelayanan yang dikenal dengan model SERVQUAL yaitu Keterhandalan (Reability), Daya Tanggap (Responsibility), Kepastian (Assurance), Perhatian (Empathy) dan Tampilan (Tangible).

Bagi Perusahaan Umum Pegadaian, lima dimensi kualitas pelayanan tersebut telah dijadikan rujukan strategi pemasaran yang diterapkan oleh perusahaan dan merupakan kunci utama untuk meningkatkan kepuasaan nasabah yang pada akhirnya berujung pada loyalitas nasabah. Masalah dalam penelitian ini adalah apakah factor bukti Fisik (Tangible), Jaminan (Assurance), Kepedulian (Emphaty), berpengaruh signifikan terhadap kepuasaan nasabah pada PERUM Pegadaian Cabang Masamba. Tujuan dilakukannya penelitian adalah sebagai berikut : Untuk membuktikan apakah kualitas pelayanan yang diukur dengan bukti Fisik (Tangible), Jaminan (Assurance), Kepedulian (Emphaty), berpengaruh terhadap kepuasaan nasabah pada PERUM Pegadaian Cabang Masamba dan untuk menganalisis factor yang berpengaruh dominan terhadap kepuasan nasabah pada PERUM Pegadaian Cabang Masamba. 


\section{Metodologi Penelitian}

Lokasi dan Waktu Penelitian

Penelitian ini dilaksanakan pada Kantor Perusahaan Umum Pegadaian Cabang Masamba Kabupaten Luwu Utara. Penelitian dimulai pada bulan Januari sampai dengan April tahun 2012.

Jenis dan Sumber data

Data yang diperlukan dalam penelitian ini meliputi:

1. Data primer adalah data yang bersumber secara langsung dari pada para responden (nasabah pada PERUM pegadaian cabang Masamba) yang terkait dengan variable penelitian.

2. Data sekunder adalah data yang diolah atau diperoleh dari dokumen atau laporan tertulis lainnya yang dipandang relevan dengan penelitian ini.

Populasi dan Sampel

Populasi dalam penelitian ini yaitu seluruh nasabah PERUM pegadaian cabang Masamba (diambil secara acak) yang menggunakan layanan PERUM pegadaian pda bulan januari 2011 sampai bulan april 2012. Sampel merupakan sub elemen kelompok populasi yang terpilih untuk berpartisipasi dalam penelitian. Agar sampel yang dapat diambil representatif, maka jumlah sampel dalam penelitian berkisar 30500 .

Kriteria nasabah yang dijadikan sampel dalm penelitian yaitu:

- Sudah terdaftar dalam PERUM pegadaian cabang Masamba terhitung mulai dari bulan Januari sampai dengan Desember 2011.

- Nasabah PERUM pegadaian cabang Masamba yang melakukan transaksi lebih dari dua kali dalam sebulan terhitung mulai dari bulan Januari sampai dengan September 2011.

Metode Pengumpulan Data

Metode pengumpulan data yang digunakan dalam penelitian ini adalah : (a) Teknik kuisioner yaitu tehnik pengumpulan data yang diperoleh dengan mengajukan daftar pertanyaan kepada responden, (b) Teknik Wawancara yaitu pengumpulan data yang diperoleh melalui Tanya jawab secara langsung dengan responden, (c) Teknik Observasi yaitu teknik pengumpulan data dengan cara melakukan pengamatan secara langsung terhadap objek penelitian, (c) Teknik Dokumentasi yaitu suatu metode pengumpulan data dengan melihat catatan tertulis dan dapat dipertanggung jawabkan serta menjadi alat bukti yang resmi.

Metode Analisis Data

Metode analisis yang digunakan dalam penelitian ini adalah pendekatan kuantitatif dengan model regresi linier berganda dengan formulasi sebagai berikut: 
Di mana :

$$
Y=\beta_{0}+\beta_{1} X_{2}+\beta_{2} X_{2}+\beta_{3} \beta_{3}+e i
$$

$\begin{array}{ll}\mathrm{Y} & =\text { Kepuasan Nasabah Pegadaian Masamba } \\ \beta_{0} & =\text { Nilai Intersepsi (Konstanta) } \\ \beta_{1}-\beta_{3} & =\text { Koefisien Regresi } \\ X_{1} & =\text { Bukti Fisik (Tangible) } \\ X_{2} & =\text { Jaminan (Assurance) } \\ X_{3} & =\text { Kepedulian (Emphaty) } \\ \mathrm{ei} & =\text { Eror (Tingkat kesalahan) }\end{array}$

Uji Validitas Realibilitas

Uji validitas dan uji reliabilitas dilakukan untuk item-item pertanyaan dari kuesioner yang digunakan dalam suatu penelitian. Hasil uji validitas dan realibilitas dari item pertanyaan tersebut akan menentukan kualitas instrumen penelitian (kuesioner) sangat penting untuk dilakukan.

Hasil Uji Validitas

Hasil uji validitas sebagaimana pada table berikut ini :

Table 5

Hasil Korelasi Pearson Untuk Variabel Bebas Bukti Fisik (X1)

\begin{tabular}{|ll|r|r|r|r|}
\hline & \multicolumn{1}{|c|}{$\mathrm{x} 1.1$} & $\mathrm{x} 1.2$ & $\mathrm{x} 1.3$ & \multicolumn{1}{c|}{$\mathrm{X} 1$} \\
\hline $\mathrm{x} 1.1$ Pearson Correlation & 1 & .665 & .603 & .885 \\
& Sig. (2-tailed) & & .000 & .000 & .000 \\
& $\mathrm{~N}$ & 50 & 50 & 50 & 50 \\
\hline $\mathrm{x} 1.2$ & Pearson Correlation & .655 & 1 & .548 & .871 \\
& Sig. (2-tailed) & .000 & & .000 & .000 \\
& $\mathrm{~N}$ & 50 & 50 & 50 & 50 \\
\hline x1.3 & Pearson Correlation & .603 & .548 & 1 & .813 \\
& Sig. (2-tailed) & .000 & .000 & & .000 \\
& $\mathrm{~N}$ & 50 & 50 & 50 & 50 \\
\hline X1 & Pearson Correlation & .885 & .871 & .813 & 1 \\
& Sig. (2-tailed) & .000 & .000 & .000 & \\
& $\mathrm{~N}$ & 50 & 50 & 50 & 50 \\
\hline
\end{tabular}

Variable bebas jaminan terdiri dari tiga item pertanyaan (x1.1, x.1.2, dan x.1.3) dan masing-masing menghasilkan total nilai skor untuk 50 responden. hasil uji korelasi person menunjukkan bahwa seluruh pertanyaan yang disusun dalam kuesioner untuk variable bebas bukti fisik (X1) seluruhnya valid. 
Tabel 6

Hasil Korelasi Pearson untuk Variabel Jaminan (X2)

\begin{tabular}{|c|c|c|c|c|c|}
\hline & $\mathrm{X} 2.1$ & $\mathrm{X} 2.2$ & $\mathrm{X} 2.3$ & $\mathrm{X} 2$ \\
\hline \multirow[t]{3}{*}{$\mathrm{X} 2.1$} & Pearson Correlation & 1 & .585 & .549 & .825 \\
\hline & Sig. (2-tailed) & & .000 & .000 & .000 \\
\hline & $\mathrm{N}$ & 50 & 50 & 50 & 50 \\
\hline \multirow[t]{3}{*}{$\mathrm{X} 2.2$} & Pearson Correlation & .585 & 1 & .588 & .874 \\
\hline & Sig. (2-tailed) & .000 & & .000 & .000 \\
\hline & $\mathrm{N}$ & 50 & 50 & 50 & 50 \\
\hline \multirow[t]{3}{*}{$\mathrm{x} 2.3$} & Pearson Correlation & .549 & .588 & 1 & .838 \\
\hline & Sig. (2-tailed) & .000 & .000 & & .000 \\
\hline & $\mathrm{N}$ & 50 & 50 & 50 & 50 \\
\hline \multirow[t]{3}{*}{$\mathrm{X} 2$} & Pearson Correlation & .825 & .874 & .838 & 1 \\
\hline & Sig. (2-tailed) & .000 & .000 & .000 & \\
\hline & $\mathrm{N}$ & 50 & 50 & 50 & 50 \\
\hline
\end{tabular}

Variabel bebas jaminan terdiri dari tiga item pertanyaan (x2.1, x.2.2, dan x.2.3) dan masing-masing menghasilkan total nilai skor untuk 50 responden. hasil uji korelasi person menunjukkan bahwa seluruh pertanyaan yang disusun dalam kuesioner untuk variable Jaminan (X2) seluruhnya valid.

Tabel 7

Hasil Korelasi Pearson untuk Variabel Kepedulian (X3)

\begin{tabular}{|c|c|c|c|c|c|}
\hline & $\mathrm{X} 3.1$ & $\mathrm{X} 3.2$ & X3.3 & $\mathrm{X} 3$ \\
\hline \multirow{3}{*}{\multicolumn{2}{|c|}{$\begin{array}{ll}\text { X3.1 } & \text { Pearson Correlation } \\
& \text { Sig. (2-tailed) } \\
& \text { N }\end{array}$}} & 1 & .414 & .567 & .798 \\
\hline & & & .000 & .000 & .000 \\
\hline & & 50 & 50 & 50 & 50 \\
\hline \multirow[t]{3}{*}{$\mathrm{X} 3.2$} & Pearson Correlation & .414 & 1 & .374 & .827 \\
\hline & Sig. (2-tailed) & .000 & & .000 & .000 \\
\hline & $\mathrm{N}$ & 50 & 50 & 50 & 50 \\
\hline \multirow[t]{3}{*}{ X3.3 } & Pearson Correlation & .567 & .374 & 1 & .744 \\
\hline & Sig. (2-tailed) & .000 & .000 & & .000 \\
\hline & $\mathrm{N}$ & 50 & 50 & 50 & 50 \\
\hline & Pearson Correlation & .798 & .827 & .744 & 1 \\
\hline & Sig. (2-tailed) & .000 & .000 & .000 & \\
\hline & $\mathrm{N}$ & 50 & 50 & 50 & 50 \\
\hline
\end{tabular}

Variabel bebas Kepedulian terdiri dari tiga item pertanyaan (x3.1, x.3.2, dan x.3.3) dan masing-masing menghasilkan total nilai skor untuk 50 responden. hasil uji korelasi person menunjukkan bahwa seluruh pertanyaan yang disusun dalam kuesioner untuk variabel Kepedulian (X3) seluruhnya valid. 
Tabel 8

Hasil Korelasi Pearson untuk Variabel Terikat kepuasan Nasabah (Y)

\begin{tabular}{|c|c|c|c|c|c|}
\hline & y1 & y2 & $\mathrm{y} 3$ & $\mathrm{Y}$ \\
\hline \multirow[t]{3}{*}{ X3.1 } & Pearson Correlation & 1 & .536 & .409 & .770 \\
\hline & Sig. (2-tailed) & & .000 & .000 & .000 \\
\hline & $\mathrm{N}$ & 50 & 50 & 50 & 50 \\
\hline \multirow[t]{3}{*}{$\mathrm{X} 3.2$} & Pearson Correlation & .536 & 1 & .582 & .893 \\
\hline & Sig. (2-tailed) & .000 & & .000 & .000 \\
\hline & $\mathrm{N}$ & 50 & 50 & 50 & 50 \\
\hline \multirow[t]{3}{*}{ X3.3 } & Pearson Correlation & .409 & .582 & 1 & .792 \\
\hline & Sig. (2-tailed) & .000 & .000 & & .000 \\
\hline & $\mathrm{N}$ & 50 & 50 & 50 & 50 \\
\hline \multirow[t]{3}{*}{$\mathrm{X} 3$} & Pearson Correlation & .770 & .893 & .792 & 1 \\
\hline & Sig. (2-tailed) & .000 & .000 & .000 & \\
\hline & $\mathrm{N}$ & 50 & 50 & 50 & 50 \\
\hline
\end{tabular}

Variabel terikat kepuasan nasabah terdiri dari tiga item pertanyaan (y1, y2, dan y3) dan masing-masing menghasilkan total nilai skor untuk 50 responden. hasil uji korelasi person menunjukkan bahwa seluruh pertanyaan yang disusun dalam kuesioner untuk variabel terikat kepuasan nasabah (Y) seluruhnya valid.

Hasil Uji Reabilitas

Untuk menguji reliabilitas instrument pengukuran digunakan prosedur Cronbach's Alpha. Suatu konstruk atau variabel dikatakan reliable jika memberikan nilai Ccronbach Alpha > 0,60. Adapun hasil perhitungan reliabilitas yaitu:

Tabel 9

Hasil Uji Realiabilitas untuk Variabel Bebas (X1, X2 dan X3), Variabel Terikat Y

\begin{tabular}{|c|c|c|c|}
\hline NO & Variabel & Hasil Alpha & Keterangan \\
\hline 1 & $\mathrm{X} 1$ & 0,819 & Reliabel \\
\hline 2 & $\mathrm{X} 2$ & 0,802 & Reliabel \\
\hline 3 & $\mathrm{X} 3$ & 0,712 & Reliabel \\
\hline 6 & $\mathrm{Y}$ & 0,757 & Reliabel \\
\hline
\end{tabular}

Sumber Data : Lampiran 4

Hasil pengujian Validitas dan Realiabilitas menyimpulkan bahwa seluruh butir pertanyaan berstatus valid untuk setiap variabel penelitian, dan realibilitas untuk seluruh variabel. Maka seluruh data skor yang dihasilkan dapat digunakan untuk proses analisis regresi dan uji statistic selanjutnya. 


\section{Hasil Penelitian Dan Pembahasan}

\section{Hasil Persamaan Regresi}

Tabel 10

Hasil Persamaan Regresi

\begin{tabular}{|ll|c|c|c|c|c|}
\hline \multirow{2}{*}{ Model } & \multicolumn{2}{|c|}{ Unstandardized Coefficients } & $\begin{array}{c}\text { Standardized } \\
\text { Coefficients }\end{array}$ & & \\
\cline { 2 - 5 } & $\mathrm{B}$ & Std. Eror & Beta & $\mathrm{t}$ & $\mathrm{S}$ Sig \\
\hline 1 & (Constant) & -4.061 & 3.073 & & -1.321 & .193 \\
& $\mathrm{X} 1$ & .103 & .137 & .078 & .748 & .459 \\
$\mathrm{X} 2$ & .337 & .150 & .232 & .2 .248 & .029 \\
$\mathrm{~N} 3$ & .795 & .119 & .690 & .6 .694 & .000 \\
\hline
\end{tabular}

$\mathrm{Y}=(-4,061)+0,103 \mathrm{X}_{1}+0,337 \mathrm{X}_{2}-0,795 \mathrm{X}_{3}$

Dimana masing-masing regresi tersebut mempunyai arti sebagai berikut :

$\mathrm{b}_{0}=(-4,061)$

Mempunyai arti $\mathrm{X}_{1} ; \mathrm{X}_{2} ; \mathrm{X}_{3}=0$ maka kepuasan nasabah PERUM Pegadaian Cabang Masamba mengalami penurunan sebesar $(-4,061)$.

$\mathrm{b}_{1}=0,103 \mathrm{X}_{1}$ artinya variabel bukti $\left(\mathrm{X}_{1}\right)$ mempunyai oengaruh positif terhadap kepuasan nasabah PERUM pegadain Masamba.

$\mathrm{b}_{2}=0,337 \mathrm{X}_{2}$

variabel kepedulian $\left(\mathrm{X}_{2}\right)$ mempunyai pengaruh positif terhadap kepuasan nasabah.

$\mathrm{b}_{3}=0,795 \mathrm{X}_{3}$

artinya variabel daya taggap $\left(\mathrm{X}_{3}\right)$ mempunyai pengaruh positif tehadap kepuasan nasabah.

b. Analisis Koefisien Determinasi $\left(\mathrm{R}^{2}\right)$

Tabel 11

Koefisien Determinasi $\left(\mathrm{R}^{2}\right)$

\begin{tabular}{|c|c|c|c|c|}
\hline Model & $\mathrm{R}$ & R. Square & $\begin{array}{c}\text { Adjusted R } \\
\text { Square }\end{array}$ & $\begin{array}{c}\text { Std. Eror Of } \\
\text { The Estimate }\end{array}$ \\
\hline 1 & $-718^{\mathrm{a}}$ & .515 & .484 & 1.88709 \\
\hline
\end{tabular}

Sumber data : Lampiran 5 
Pengujuian secara serempak

Maksud pengujian ini adalah untuk mengetahuai bagaimana variabel bebas yang terdiri variabel bukti fisik (X1) jaminan (X2) dan kepedulian (X3), secara bersamasama berpengaruh terhadap variabel terikat yakni kepuasan nasabah PERUM pegadaian cabang masamba $(\mathrm{Y})$.

Pengujian seacara partial

Pengujian secara partial (uji - t) yaitu untuk mengetahuitingkat signifikan antar variabel terikat secara statistik.

\section{Pembahasan}

Berdasarkan uji $\mathrm{F}$ dalam analisis regresi linier brganda pada penelitian ini diketahui bahwa tingkat signifikan sebesar 0,000 $\alpha$ lebih kecil dibandingkan dengan tingkat a $=5 \%$ berarti semua variabel bebas yang meliputi bukti fisik (X1), jaminan (X2), dan kepedulian (X3) mempunyai pengaruh yang signifikan terhadap variabel kepuasan nasabah (Y).

Faktor-faktor yang meliputi bukti fisik (X1), jaminan (X2), dan kepedulian (X3) terhadap kepuasan nasabah (Y) sebesar 0,515 atau 51,5\%. Dengan demikian dapat disimpulkn bahwa perubahan kepuasan nasabah dalam PERUM pegadain cabang masamba dipengaruhi oleh factor lain secara variabel bebas pada penelitian ini sebesar 0,485 ataau $48,5 \%$.

Berdasarkan hasil regresi linier brganda untuk uji t diketahui bahwa tingkat signifiakn masing-masing variabel yaitu bukti fisik $(\mathrm{X} 1=0,459)$, bang jaminan $(\mathrm{X} 2$ $=0,029)$, kepedulian $(X 3=0,000)$. Dari hasil tersebut terdapat 2 variabel yang dapat membuktiakn hipotesis bahwa dimensi kualitas layana bukti fisik, jaminan dan kepedulian berpegaruh terhadap kepuasan nasabah pada PERUM pegadaian cabang Masamba.

Besarnya pengaruh dari masing-masing faktor mempunyai pengaruh terhadap kepuasan nasabah pada PERUM pegadaian cabang Masamba secara barturut-turut yaitu (1). kepedulian (X3) mempunyai pengaruh positif signifikan sebesar $=0,765$ artinya nasabah akan menyarankan kepada orang lain dalam menggunakan jasa PERUM pegadain cabang Masamba dari segi kepedulian yang dimilikinya. (2). Jaminan (X2) mempunyai pengaruh signifikan sebesar $=0,337$ artinya nasabah akan menyarankan kepada orang lain dalam menggunakan jasa PERUM pegadaian cabang Masamba dari segi jaminan seperti adanya perasaan aman dalam melakukan transaksi, berkelakuan baik secara konsisten yang diperlihatkan oleh karyawan terhadap nasabah, serta karyawan mampu memberikan pelayanan yang menumbuhkan keyakinan nasabah yang dimiliki oleh Perumj pegadaian cabang Masamba.

Sedangkan bukti fisik (X1) mempunyai pengaruh positif tidak signifikan sebesar $=10,3 \%$ artinya nasabah akan lebih mempertimbangakan lagi dalm menggunakan 
jasa PERUM pegadaian cabang Masamba yang mencakup adanya penyedian sarana seperti kantor dan lahan parker, penempilan karyawan, dan penggunaan teknologi yang dinilai masih perlu ditingkatkan lagi oleh PERUM pegadaian cabang Masamba.

Berdasarkan besarnya pengaruh masing-masing faktor-faktor tersebut terhadap kepuasan nasabah, maka akan dapaat disimpulkan bahwa faktor kepedulian (X3) yang mempunyai pengaruh paling dominan terhadap kepuasan nasabah PERUM pegadaian cabang Masamba.

\section{Penutup}

Kesimpulan penelitian ini adalah bahwa adanya pengaruh faktor-faktor bukti fisik (X1), jaminan (X2), dan kepedulian (X3) secara bersama-sama berpengaruh signifikan terhadap kepuasan nasabah (Y). berdasarkan hasil regresi linear berganda untuk uji t diketahui bahwa tingkat signifiakn untuk msing-masing variabel untuk yaitu bukti fisik $(\mathrm{X} 1=0,459)$, jaminan $(\mathrm{X} 2=0,029)$, dan kepedulian $(\mathrm{X} 3=0,000)$. Dari hasil tersebut terdapat dua variabel yang dapat membuktikan hipotesis yang menduga bahwa dimensi kualitas layanan bukti fisik, jaminan, dan kepedulian berpengaruh signifikan terhadap nasabah pada PERUM pegadaian Masamba yaitu variabel jaminan (X2) dan kepedulian (X3) sedangkan satu variabel lainnya yaitu bukti fisik (X1) tidak diterima atau tidak terbukti kebenarannya. Saran dari penelitian ini adalah bahwa Pimpinan PERUM pegadaian cabang masamba memiliki evektivitas yang belum maksimal dalam membangkitkan kepuasan nasabah khususnya dalam aspek : bukti fisik yang dapat dilihat dari pengaruh terhadap kepuasan masabah masih belum bisa memberikan nilai yang maksimal sehingga harus menjadi perhatian yang diperioritaskan untuk lebih ditingkatkan lagi misalnya dalam penyediaan sarana seperti kantor yang letaknya strategis yang tidak menyulitkan nasabah serta lahan parkir yang luas agar bisa dijadikan acuan bagi cabang-cabang PERUM pegadaian yang lama dan baru direncanakan.

\section{Daftar Pustaka}

Augusty Ferdinad.2006.Metode Penelitian Manajemen : Pedoman Penelitian untuk Penulusuran Skripsi, Tesis, dan Desertasi Ilmu : Badan Penerbit Universitas di Ponegoro.

Asep M.ramdan. 2008 Oktober 22.”Hubungan Kualitas Jasa dan kepuasan Konsumen" 
Ayu Wulandari. 2009. “Pengaruh Promosi Tingkat Penjualan Minuman Yakult pada PT. Yakult Indonesia Persada cabang Padang", Skripsi tidak dipublikasikan. STIE Dharma Andalas. Padang.

Bernadine. 2005. "Analisis Pengaruh Kualitas Layanan Terhadap Kepuasan Pelanggan Studi Kasus pada Rumah makan Perusahaan, vol. 12, no.3 September 2005.

Freddy Rangkuti.2002.Measuring Costumer Satisfaction (cetakan ketiga). Jakarta : PT. Gramedia Pustaka Utama.

Hasan. 2006. "Pengaruh Kualitas Jasa Bank Syariah Terhadap Kepuasan Nsabah pada Bank Muamalt Indonesia Cabang Semarang”. Jurnal Ekonomi dan Bisnis, vol. no. 1 April 2006.

Kotler, Philip dan A.B Susanto.2000. Manajemen Pemasaran Jasa di Indonesia, Analisis Perancanaan, Implementasi dan Pengendalian (Edisi pertama). Jakarta : Salemba Empat. 2001. Manajemen Pemasaran Jasa di Indonesia (buku 2). Jakarta salemba Empat.

Nanang Tasunar. 2006. “Kualitas Layanan Sebagai Strategi Menciptakan Kepuasan pada pangkalan Pendaratan ikan (PPI) Morodemak". Jurnal Sains Pemasaran Indonesia.

Rambat Lupiyoadi. 2004. Manajemen Pemasara Jasa : Toeri Praktek. Jakarta: PT Salemba Empat. 